\title{
Influence of vacuum level on insulation thermal performance for LNG cryogenic road tankers
}

\author{
Lisowski Edward ${ }^{1}$, Lisowski Filip ${ }^{2 *}$ \\ ${ }^{1}$ Cracow University of Technology, Institute of Applied Informatics \\ ${ }^{2}$ Cracow University of Technology, Institute of Machine Design
}

\begin{abstract}
In this paper, thermal properties of materials for evacuated insulation systems of double-walled cryogenic tanks were discussed. Than the comparison of insulation variants for LNG cryogenic road tankers was presented. The use of several layers of insulation made of materials such as aerogel and fiberglass or the use of multilayer isolation (MLI) has been compared to the use of perlite powder. The average heat flux through the tank walls and insulation system has been compared under different vacuum levels and in the absence of vacuum. The comparative analysis was performed by applying transient thermal analysis using finite element method.
\end{abstract}

\section{Introduction}

Typical cryogenic road tankers consist of inner vessel and outer jacket. The evacuated annular space in between is fully or partially filled by insulation system. The thermal performance of insulation system depends on applied materials and vacuum level. The vacuum level should be constantly controlled during tanks exploitation and improved in case of pressure increase. This paper discussed the influence of vacuum level on thermal performance of different insulation systems for LNG cryogenic road tankers.

\section{Insulation materials for LNG cryogenic road tankers}

Insulation materials for cryogenic applications can be divided into three groups: foams, bulk-fill and layered [1]. Typical foams including polyurathene or polystyrene have thermal conductivity in the range of 35-55 $\mathrm{mW} /(\mathrm{mK})[2]$. However foams are rigid and flammable [3], which is not favorable for application in mobile tanks.

The bulk-fill powders insulations have been mainly used in stationary or large transportation containers. The best known natural origin microporous material is an expanded perlite with bulk density from 50 to $300 \mathrm{~kg} / \mathrm{m}^{3}$ [4] and thermal conductivity coefficient $1-2 \mathrm{~mW} /(\mathrm{mK})$ under vacuum pressure around $0,1 \mathrm{~Pa}$. [5]. Other well known powders are: glass bubbles, silica aerogels or composites. The glass bubbles have a slightly lower heat conduction coefficient than them perlite or aerogel powders. In turn, aerogel powders with microporous cellular structure have high compressive strength, but at high production costs [4]. However, the powder materials have the tendency to settle and compact due to vibration and thermal cycling loads [6].

The best thermal performance, as low as $0,03 \mathrm{~mW} /(\mathrm{mK})$, can be obtained in the laboratory conditions for multilayer insulation [7]. MLI, also known as superinsulation, requires vacuum level below $10^{-3} \mathrm{~Pa}$ to be fully effective [8]. It consists of a large number of highly reflecting shields separated by spacers having low conductivity. When the pressure distribution is very homogeneous, the local thermal conductivity between the radiation shields is strongly suppressed [9]. MLI is sensitive to mechanical compression and edge effects. The effectiveness of MLI depends on vacuum level. In case of sudden loss of vacuum, thermal performance can degrade rapidly causing a dangerous pressure increase inside the inner tank [10]. Furthermore, the steps of evacuation, heating, and vacuum retention are expensive and time consuming [6].

The other layered insulation systems that incorporate aerogel or fiberglass composite blankets can remain effective even at lower vacuum level [11]. In that case the conduction is greater and those systems will not be as efficient as MLI at higher vacuum pressure.

The aerogels are flexible, highly porous materials, which have low density and high porosity, that makes them very good insulators. However, compressive loads may affect the thermal resistance due to their structure [12]. An another material, developed as an alternative to commonly used perlite is the micro-fiberglass material Cryo-Lite ${ }^{\circledR}$. Its low density minimizes tanker weight, eliminates problem with settling or compaction and offers fast vacuum pump down rates with minimal outgassing [8]. Due to its low opacity Cryo-Lite ${ }^{\circledR}$ blankets should be used with radiation shields.

Since the effectiveness of MLI is about $50 \%$ worse at atmospheric pressure, system involving combination of MLI and aerogels [13] or MLI and fiberglass blankets

\footnotetext{
* Corresponding author: filip.lisowski@ mech.pk.edu.pl
} 
were also tested [8]. Experimental results showed that combination of different insulation materials can improve insulation system effectiveness and it was found that it is significant whether a particular material is on the warm or cold side.

\section{Modelling of the heat transfer through tanker insulation}

In order to compare thermal performacne of different insulating materials for application in LNG cryogenic road tanker, heat transfer through vary evacuated insulation systems and temperature distribution were examined by applying transient thermal analysis using Ansys software. Two dimensional models within crosssection of the tank walls and insulation system, analogous as shown in the Fig. 1 were accepted. The study included four different insulation materials in several variants as given in table 1 . Each variant was tested in three levels of the residual gas pressure (CVP): $10^{-1} \mathrm{~Pa}, 10^{-3} \mathrm{~Pa}$ and $100 \mathrm{kPa}$.

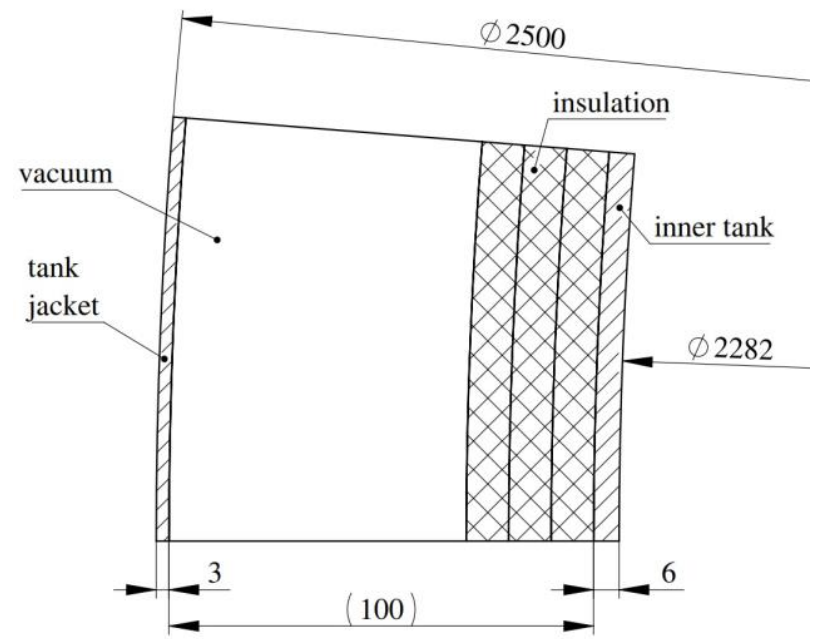

Fig. 1. Cross-section of the exemplary insulation system

Table 1. Variants of the tested insulation systems

\begin{tabular}{|c|c|c|}
\hline $\begin{array}{c}\text { Insulation } \\
\text { material }\end{array}$ & $\begin{array}{c}\text { Number } \\
\text { of layers }\end{array}$ & $\begin{array}{c}\text { Insulation } \\
\text { thickness [mm] }\end{array}$ \\
\hline Cryogel $^{\circledR} \mathrm{Z}$ & 2 & 20 \\
\hline Cryogel $^{\circledR} \mathrm{Z}$ & 6 & 60 \\
\hline Cryogel $^{\circledR} \mathrm{Z}$ & 10 & 100 \\
\hline Cryo-Lite $^{\circledR}$ & 1 & 25 \\
\hline Cryo-Lite $^{\circledR}$ & 2 & 50 \\
\hline Cryo-Lite $^{\circledR}$ & 5 & 100 \\
\hline MLI & 40 & 16 \\
\hline Perlite & - & 100 \\
\hline
\end{tabular}

\subsection{Material properties}

A stainless steel 1.4301 was accepted as a material of inner vessel and outer jacket. The coefficient of thermal conductivity in the function of temperature for steel 1.4301 is shown in the Fig. 3, whereas for insulating materials such as Cryo-Lite ${ }^{\circledR}$ and Cryogel ${ }^{\circledR} \mathrm{Z}$ in the Fig. 2 (vendor data). MLI insulation consisted of 40 layers of double-aluminized Mylar and polyester net spacer. An expanded perlite accepted for analysis has bulk density of $200 \mathrm{~kg} / \mathrm{m} 3$. The coefficients of thermal conductivity in the function of pressure for MLI and perlite are given in table 2 .

Table 2. Coefficients of thermal conductivity for MLI and perlite in the function of pressure [8].

\begin{tabular}{|c|c|c|}
\hline Material & $\mathbf{k}[\mathbf{m K} / \mathbf{m} \cdot \mathbf{K}]$ & $\mathbf{C V P}[\mathbf{P a}]$ \\
\hline MLI & 0,028 & $10^{-3}$ \\
\hline MLI & 0,072 & $10^{-1}$ \\
\hline MLI & 35 & $10^{5}$ \\
\hline Perlite & 0,95 & $10^{-3}$ \\
\hline Perlite & 1 & $10^{-1}$ \\
\hline Perlite & 44 & $10^{5}$ \\
\hline
\end{tabular}

\subsection{Assumptions for numerical analysis}

- the model is in a state of thermal equilibrium,

- the internal surface of inner tank exchanges heat with liquid by convection with accepted convection coefficient $337 \mathrm{~W} /(\mathrm{m} 2 \mathrm{~K})$ at $77 \mathrm{~K}$ [14],

- the external surface of tank jacket exchanges heat with environment by convection with accepted convection coefficient $8,89 \mathrm{~W} /(\mathrm{m} 2 \mathrm{~K})$ at $293 \mathrm{~K}$ [14],

- heat is transferred through insulation layers only by conduction with accepted coefficient of thermal conductivity,

- for residual gas pressure of $10-1 \mathrm{~Pa}$ and $100 \mathrm{kPa}$, heat is transferred by conduction and by radiation,

- for residual gas pressure of 10-3 Pa, heat is transferred through residual gas only by radiation,

- for layered insulation systems, external layer of insulation is covered with an aluminum radiation shield with emissivity $\varepsilon=0,03$ [9],

- surface to surface model of radiation was accepted.

Coefficient of thermal conductivity of residual gas under pressure of $10^{-1} \mathrm{~Pa}$ was assumed equal to $0,01 \mathrm{~W} /(\mathrm{mK})$ [4]. For the case of no vacuum, the assumed gas pressure of $100 \mathrm{kPa}$ corresponds to atmospheric pressure. Coefficient of thermal conductivity in the function of temperature for dry air was accepted as presented in the Fig. 4.

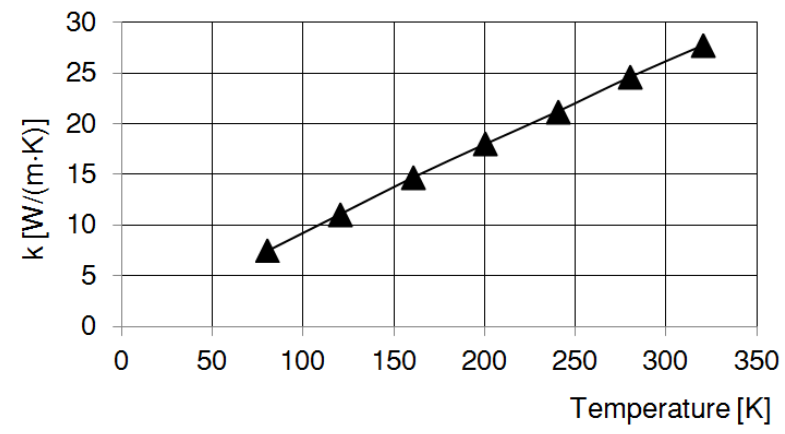

Fig. 4. Thermal conductivity of dry air at $100 \mathrm{kPa}$ [15] 


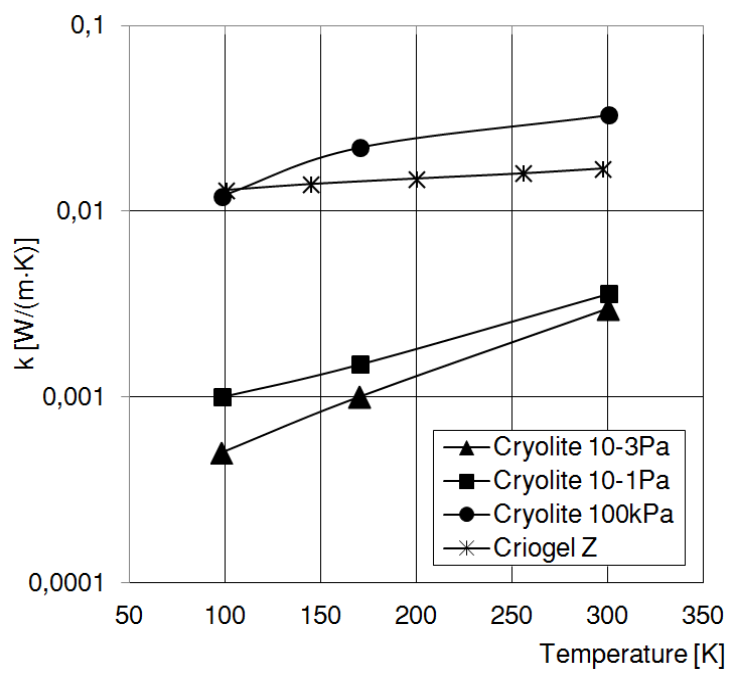

Fig. 2. Thermal conductivity of Cryo-Lite ${ }^{\circledR}$ and Cryogel ${ }^{\circledR} Z$

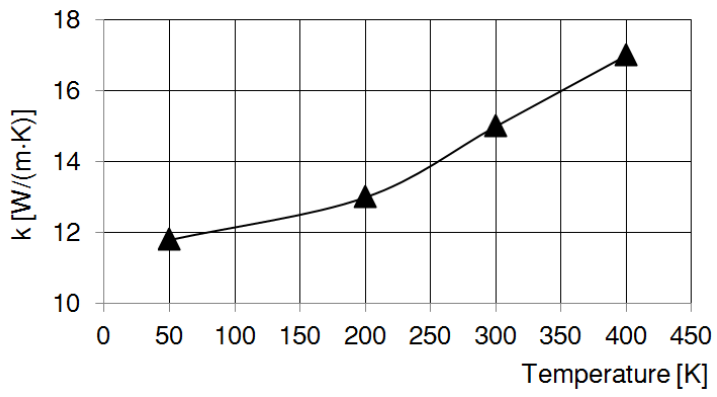

Fig. 3. Thermal conductivity of stainless steel 1.4301 [16]

\subsection{Simulation results}

The comparative results of the transient thermal analysis are presented in diagrams as well as in the maps of heat flux and temperature distribution. The exemplary results of heat flux and temperature distribution in the cross-section of insulation system involving Cryo-Lite ${ }^{\circledR}$ under vacuum pressure of $10^{-1} \mathrm{~Pa}$ are shown in the Fig. 5. and Fig. 6. Average heat flux in the cross-section of the inner tank wall for insulation systems containing Cryo-Lite $^{\circledR}$ and Cryogel $^{\circledR}$ insulation blankets are summarized in the Fig. 7 and Fig. 8. Fig. 9 presents results for insulation systems including MLI, perlite and only residual gas.

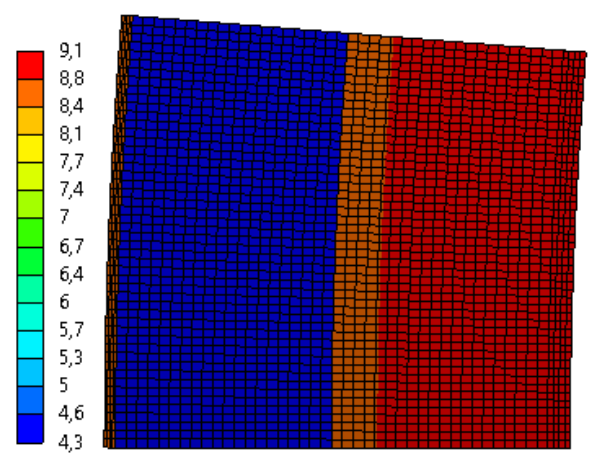

Fig. 5. Heat flux distribution in the cross section of insulation system with Cryo-Lite ${ }^{\circledR}$ under vacuum pressure of $10^{-1} \mathrm{~Pa}$

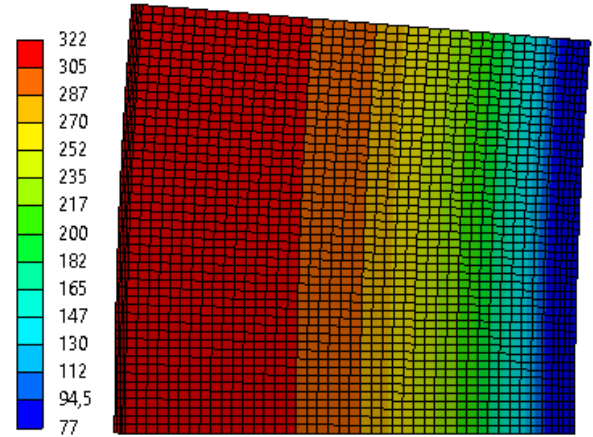

Fig. 6. Temperature distribution in the cross section of insulation with Cryo-Lite ${ }^{\circledR}$ under vacuum pressure of $10^{-1} \mathrm{~Pa}$

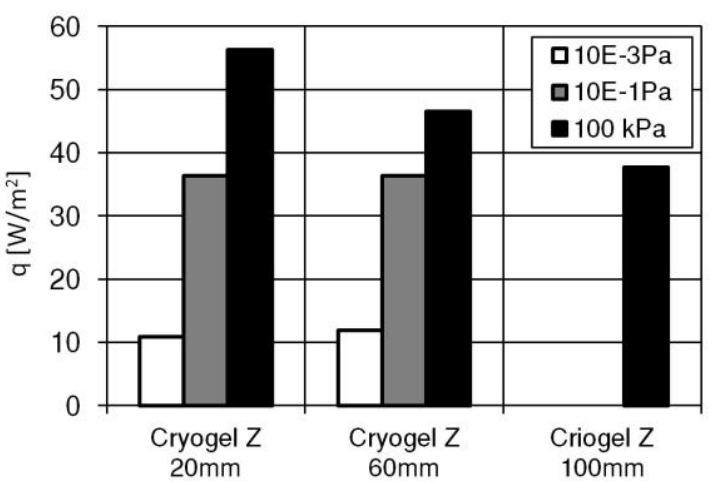

Fig. 7 Average heat flux in the cross-section of inner tank wall for insulation system with $\mathrm{Cryogel}^{\mathbb{B}} \mathrm{Z}$

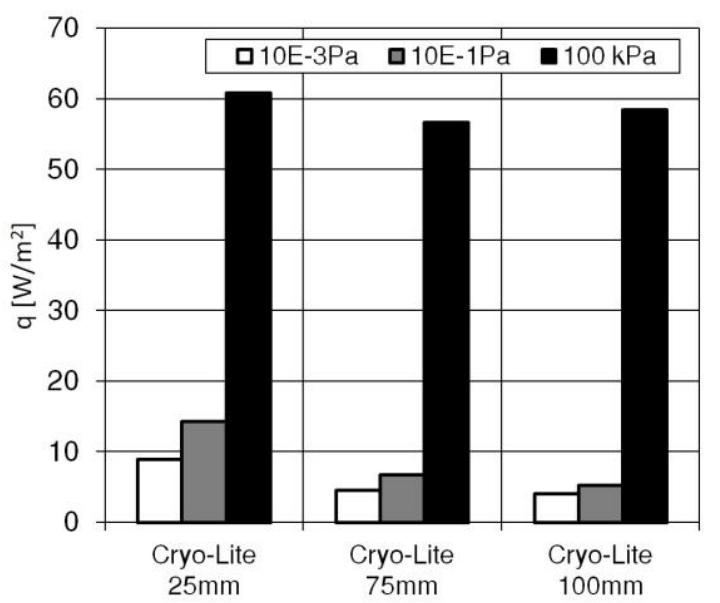

Fig. 8. Average heat flux in the cross-section of inner tank all for insulation system with Cryo-Lite ${ }^{\circledR}$

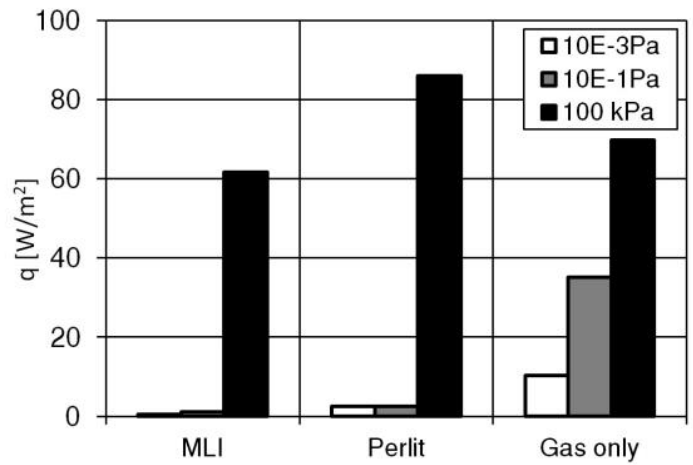


Fig. 9. Average heat flux in the cross-section of inner tank wall for insulation systems with MLI, perlite and gas only

\section{Results and discussion}

The results of thermal analysis of 2D models show that multilayer insulation (MLI) system in comparison with other tested cryogenic insulation systems is the best performer in the high vacuum (HV) range under residual gas pressure of $10^{-3} \mathrm{~Pa}$ and in the soft vacuum (SV) range under pressure of $10^{-1} \mathrm{~Pa}$. Bulk-fill expanded perlite is the second, followed by the fiberglass and aerogel blankets. Cryogel ${ }^{\circledR}$ aerogel insulation blanket is the best performer in the range of no vacuum (NV) under pressure of $100 \mathrm{kPa}$. The insulation system with Cryo-Lite ${ }^{\circledR}$ fiberglass blankets had slightly worse thermal performance than insulation systems with MLI and perlite in the soft and high vacuum, but it was better in no vacuum range.

\section{Conclusions}

The liquefied natural gas is condensated at - $162{ }^{\circ} \mathrm{C}$. In order to maintain a liquid state of gas, it is important to keep its proper temperature level throughout the storage period. Therefore the thermal insulation of LNG cryogenic tanks plays an important role. Its effectiveness depends on applied materials and pressure of residual gas. The presented analysis has shown that already the usage of vacuum significantly reduce heat leakage to the inner tank. In addition the use of modern insulating materials allows to control the heat flux passing through the walls of the tank and insulation system. However, it should be noticed, that the thermal analysis of the whole structure of LNG cryogenic road tankers should be extended to include the analysis of heat flux passing both through the tank walls and through the internal supports between inner tank and outer jacket.

\section{REFERENCES}

1. J.E Fesmire, S.D Augustynowicz, Cryogenic Thermal Insulation Systems, 16th Thermal and Fluids Analysis Workshop, Orlando, (2005)

2. M. Chorowski, Cryogenics Fundamentals and Applications, IPPU Masta, Gdańsk (in Polish) (2005)

3. A. Bahadori, Thermal Insulation Handbook for Oil, Gas and Petrochemical Industries, Elsevier (2014)

4. U. Bünger, G. Owren, Development potentials for small mobile tanks with vacuum powder insulations, International Journal of Hydrogen Energy, pp. 259279, 4 (1998)

5. T.M. Flynn, Cryogenic engineering. Second Edition, Marcell Dekker, New York (2005)

6. S.D Augustynowicz, J.E. Fesmire, J.P.Wikstrom, Cryogenic Insulation Systems, 20th International Congress of Refrigeration, Sydney (1999)
7. J.E. Fesmire, Standardization in cryogenic insulation systems testing and performance data, Physics Procedia, pp. 1089-1097, 67 (2015)

8. A. Kogan, , J.E. Fesmire W. Johanson, J. Minnick, Cryogenic Vacuum Insulation for Vessels and Piping, NASA Technical Report, Nr. KSC-2010-126 (2010)

9. H. Reiss, A coupled numerical analysis of shield temperatures, heat losses and residual gas pressures in an evacuated super-insulation using thermal and fluid networks Part I: Stationary conditions., Cryogenics, pp. 259-279, 44 (2004).

10. G.F. Xie, X.D. Li, R.S. Wang, Study on the heat transfer of high-vacuum-multilayer-insulation tank after sudden, catastrophic loss of insulating vacuum, Cryogenics, pp. 682-687, 50 (2010).

11. B. E. Coffman, J.E. Fesmire, S. White, G. Gould, S. Augustynowicz, Aerogel blanket insulation materials for cryogenic applications, Advances in Cryogenics Engineering AIP Conf. Proc., pp. 913-920, 1218 (2010)

12. A. Hoseini, A. Melekian, M. Bahrami, Deformation and thermal resistance study of aerogel blanket insulation material under unaxial compression, Energy and Buildings, pp. 228-237, 130 (2016)

13. W. L. Johnson, J. A. Demko, J. E. Feasmire, Analysis and testing of multilayer and aerogel insulation configurations, Advances in Cryogenics Engineering AIP Conf. Proc., pp. 780-787, 1218 (2010).

14. W. Czyżycki, Modeling of heat flow through multilayer internal supports of cryogenic vessels, Technical Transactions, Mechanics, pp.27-34, 2-M (2015)

15. N.B. Vargaftik., L.P. Filippov, A.A. Tarzimanov, Totskii E.E., Handbook of thermal conductivity of liquids and gases, CRC Press. (2005)

16. W. Czyżycki, Heat flow modelling on thermal insulation of cryogenics tanks using SolidWorks Simulation package, Technical Transactions, Mechanics, pp.29-36, 4-M (2011) 